\section{Child sex abuse}

DeAR SiRS

I read the article 'The Diagnosis of Child Sexual Abuse' by Arnon Bentovim (Bulletin, September 1987, 11, 295299) with great concern. There is much discussion at present about child sex abuse among doctors as a whole and also among psychiatrists. It seems we all believe in the existence of a disease like child sex abuse. I am writing this to request my colleagues to pause for a while to think about child abuse before we go any further.

As far as I know, child sexual abuse is not a disease included in the international classification of diseases. It is not an illness that is described in any major textbook of medicine, surgery, psychiatry or paediatrics. There are no uniformly agreed diagnostic criteria to make this diagnosis. The methods of investigation of a suspected case are also not clear. There is no real proof that any of the proposed suggestions of management of the case is any better than the ones that exist at present.

The whole question of child sexual abuse needs to be discussed thoroughly by doctors as a whole so that we can find answers to these issues. Only after acceptance of this as an illness, with agreed diagnostic criteria, should one talk about child sexual abuse as a disease. If the profession cannot do this and different people talk about child sexual abuse as if they are authorities in the subject, that can only confuse the issue. This is simply because the so-called experts in this field at present are self-educated enthusiasts and no wonder some of them get into trouble. There is no training for doctors in child sexual abuse at present and if we have to accept someone as an expert we should make sure that there are training centres and such experts go through a complete training programme.

St James's University Hospital

M. S. AleXander

Leeds

\section{Dr Bentovim replies}

DEAR SIRS

I read Dr Alexander's letter in response to my article with some concern. I certainly appreciate his concern about the issue of sexual abuse as a disease and how it stands within the spectrum of conditions. I would certainly agree that there could be some helpful wide ranging discussions between colleagues to try and conceptualise the issues in a more satisfactory fashion. Having now had referred something in the region of $\mathbf{8 0 0}$ families to our team at Great Ormond Street and the Tavistock Clinic, I think that it would be reasonable to say that we have had a reasonable experience of the phenomenon. In our experience we can say with some confidence that we see the sexual abuse of children as a phenomenon very closely allied to the physical abuse of children. The Battered Child Syndrome as described by Kempe is also not a disease in the formal sense of the word, although fractures, bruises and subdural haematoma etc. are diseases in their own right resulting from abusive acts which may arise from individuals who have disordered personalities or on a family level may function in ways that appear to require a victim to direct abuse at. Similarly, in sexual abuse the post-traumatic stress disorder is a clearly described DSM III diagnosis as are conduct problems, emotional disorders, personality disordered individuals, those addicted to alcohol, those with a variety of perversions who enact the abuse of children. We do have a real problem of describing family based phenomena in ways which are acceptable in a nosological sense.

There are currently attempts to develop a typology of family disorder which may bear fruit and help to categorise problems such as the sexual abuse of children in a satisfactory fashion. Meanwhile, in ICD-9 we have to think of sexual abuse as occurring on the psycho-social axis.

The problem is that the urgent question of children who have been abused, families who are inevitably caught up with child care and the legal context cannot wait for a satisfactory classification scheme before we attempt to devise appropriate ways of providing help. Psychiatrists have not always been in the forefront of the management of serious physical abuse of children. It is important that we define our role in relationship to sexual abuse and help other professionals think about the complex issues associated with it. Inevitably we have to use principles derived from other fields to gain experience to develop appropriate ways of dealing with the problems. Obviously no one can be trained in a field which does not exist until practice is defined. I hope we are now developing our practice and that the whole issue of how we conceptualise sexual abuse can be addressed.

\section{The Hospitals for Sick Children \\ Great Ormond Street \\ London $W C$}

ARnON Bentovim

\section{Canadian qualifications for British psychiatrists}

\section{DeAR SIRS}

Our Centre has been active in the recruitment of British psychiatrists for a number of years (Bulletin, April 1985, $4,77-78$ ) and we have now achieved some significant experience in the problems entailed in British psychiatrists achieving Canadian qualifications and licences to practise. It was thus with interest that we read Professor Munro's recent article (Bulletin, September 1987, 11, 305-306). Professor Munro's article implies caution in respect of prospects of immigration to Canada and upon this point we would like to amplify.

In order to obtain the Canadian qualification of LMCC, which is the licence to practise accepted by the Canadian provinces, one must pass the Canadian Qualifying Examination of the Medical Council of Canada. In order to take the Canadian Qualifying Examination it is generally necessary to pass the Canadian Evaluating Examination, unless one is already practising in Canada in which case the Evaluating 